\title{
A optimized process for the synthesis of a key starting material for etodolac, a non steroidal anti- inflammatory drug.
}

\author{
Vinodkumar R. Patel ${ }^{\mathrm{a},}$ Hemant T. desai $^{\mathrm{b}}$ \\ Research Scholar of CMJ University, Shilong, Meghalaya. \\ GM (Operations), Nirma Limited(Healthcare Division), Sachana, ahmedabad-380009
}

\begin{abstract}
An optimized process developed for the synthesis of 7-ethyltryptophol, a key starting material for etodolac, a non steroidal anti- inflammatory drug. Starting from commercially available 2ethylphenylhydrazine. $\mathrm{HCl}$ and dihydro furan with con. $\mathrm{H} 2 \mathrm{SO} 4$ as a catalyst in $\mathrm{N}, \mathrm{N}$ - dimethyl acetamide ( $D M A c)$. $H 2 O(1: 1)$ as a solvent in $75 \%$ yield the method is easy, inexpensive, without purification getting pure solid. The process is very clean, high yielding \& high quality and operationally simple.
\end{abstract}

Keywords: Etodolac, 7-ethyl tryptophol, 2-ethyl phenyl hydrazine hydrochloride, N,N-dimethyl acetamide.

\section{Introduction}

Tryptophol is a chemical compound that induces sleep in humans ${ }^{1}$. It is formed in the liver after disulfiram treatment. It is also produced by the trypanosomal parasite in sleeping sickness.tryptophol are derivatives of indole class which contain a C-3 hydroxyethyl chain ${ }^{1,2}$. Tryptophol and its derivatives are communally extracted from various natural soures ${ }^{3}$. Some of the tryptophol derivatives exhibit biological activity $^{4}$. Here 7-ethyl tryptophol is one of the important chemical moiety and it has a also pharmaceutical importance.7-ethyl tryptophol is prepare from 2-ethylphenyl hydrazine hydrochloride. 7-ethyl tryptophol mainly used for the synthesis of Etodolac 5 .

Etodolac is a nonsteroidal anti-inflammatory drug (NSAID) ${ }^{6}$. The U.S. Food and Drug Administration approved etodolac in January 1991. Etodolac is a non-steroidal anti-inflammatory drug (NSAID) with antiinflammatory, analgesic and antipyretic properties. Its therapeutic effects are due to its ability to inhibit prostaglandin synthesis. It is indicated for relief of signs and symptoms of rheumatoid arthritis and osteoarthritis ${ }^{7}$. A recent clinical trial demonstrated that etodolac was effective in improving rear limb function in dogs with chronic osteoarthritis secondary to hip dysplasia ${ }^{8}$.

7-ethyl tryptophol chemically designated as 2-(7-ethyl - 1H-indole-3-yl) ethanol, is the key intermediate for the preparation of Etodolac. But here we are prepare 7-ethyl tryptophol from 2-ethylphenyl hydrazine hydrochloride with improve the yield and quality. So we are getting better yield and quality in preparation of 7-ethyl tryptophol. The 7-ethyl tryptophol preparation has been reported by two methods. One of the reaction of 2-ethylaniline with 2,2,2- trichloroethane-1,1- diol gave the corresponding aldehyde which on further treatment with hydroxylamine hydrochloride obtained 7-ethylisatin. This intermediate is elaborated to final product, 7-ethyl tryptophol in three steps via 7-ethyl-3-indolylglyoxylate. The second method is Fischer indole synthesis of 2-ethylphenylhydrazine hydrochloride and 2, 3 dihydrofuran. The later synthetic approach reported for 7-ethyl tryptophol preparation generally carried out in water miscible solvent such as 1, 4 dioxane , THF , Etahnol, glyme, diglyme ${ }^{9,10}$. These reactions are generally handled at reflux temp. so yield \& quality both are not increase and so after all getting crude 7-ethyltryptophol is purified and we are loss another yield in this process. So while preparing the tiltle compound by the reported process e observed the inconsistency in the process, low purity and low yield, formation of various impurities in reaction mass, lengthy workup and difficulty in isolation.

\section{Result and Discussion}

As a part of our research involving synthetic process of 7-ethyl tryptophol improving method for a key intermediate of etodolac.

In our study the reaction of 2-ethylphenyl hydrazine hydrochloride with 2, 3 dihydrofuran was tested with different acid catalyst such as a PTSA, PPTSA, $\mathrm{CH} 3 \mathrm{COOH}$, and Conc. $\mathrm{H} 2 \mathrm{SO} 4$ at $50^{\circ} \mathrm{C}$ for 3-4 hrs. (Table1) 


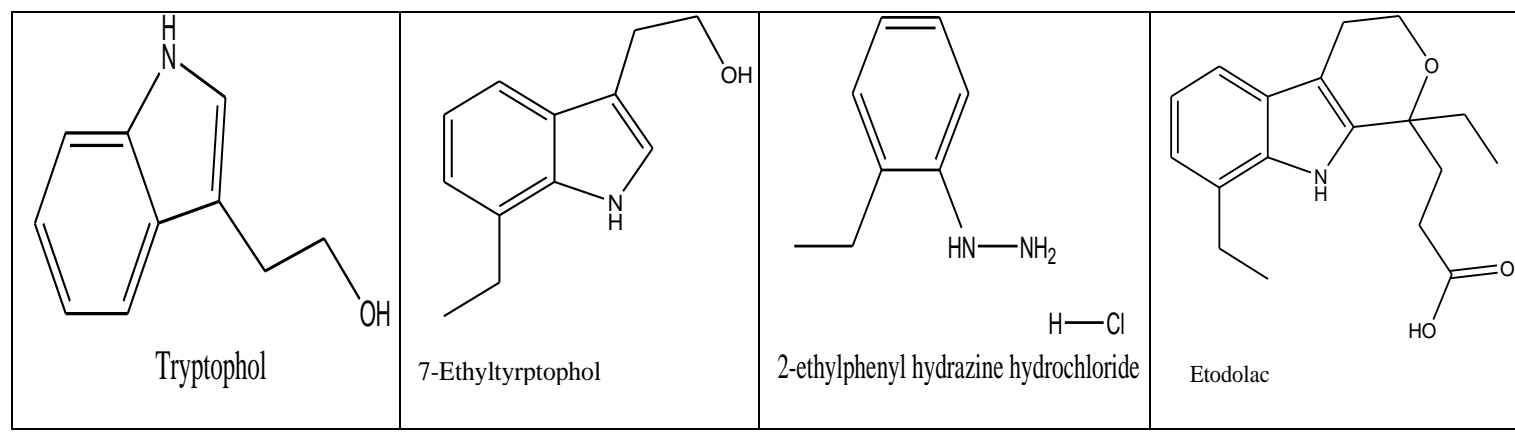

Figure 1- chemical structures of tryptophol, 7-ethyl tryptophol, 2-ethylphenyl hydrazine hydrochloride and Etodolac.

Table-1 Reaction of 2-ethylphenyl hydrazine hydrochloride with 2, 3 dihydrofuran in the presence of various acid catalysts at $50^{\circ} \mathrm{C}$.

\begin{tabular}{|l|l|l|}
\hline Sr. no. & Catalyst & $\begin{array}{l}\text { Conversion by } \\
\text { HPLC(\%) }\end{array}$ \\
\hline 1 & Conc. HCl & $42 \%$ \\
\hline 2 & Con.H2SO4 & $80 \%$ \\
\hline 3 & CH3COOH & $45 \%$ \\
\hline 4 & Trifflic acid & $58 \%$ \\
\hline 5 & PTSA & $68 \%$ \\
\hline 6 & PPTSA & $69 \%$ \\
\hline
\end{tabular}

It was found that $\mathrm{H} 2 \mathrm{SO} 4$ was superior to all the other catalyst examined and gave a good reaction conversion. During all reactions while preparing 7-ethyltryptophol, formation of a major product was observed (42-80\% by HPLC). After completion the reaction we found that at 4.5 to $5 \mathrm{pH}$ impurity not extacted in MDC. At Highly acidic $\mathrm{pH}$, Yield and purity was low and at neutral $\mathrm{pH}$ yield was good but purity was low.

A reaction scheme of 7-ethyl tryptophol shown in scheme-1. First we prepared hydrazone and then cyclized it by Conc. H2SO4. The reaction of 2-ethyl phenyl hydrazine hydrochloride and 2, 3 dihydrofuran under the present reaction conditions afforded $75 \%$ yield of the 7-etyhltryptophol.

In summary, a simple and general method for the synthesis of 7-ethyltryptophol at $45^{\circ} \mathrm{C}$, which offers several advantages including good yield has been developed.

Scheme-1<smiles>CCc1ccccc1NN</smiles>

2-ethylphenyl hydrazine. $\mathrm{HCl}$<smiles>CCc1cccc2c(CCO)c[nH]c12</smiles>

7-ethyltryptophol

Table-2 Effect of solvent on the reaction of 2-ethylphenyl hydrazine hydrochloride with 2, 3 dihydrofuran in the presence of Conc. $\mathrm{H} 2 \mathrm{SO} 4$ at $40-45^{\circ} \mathrm{C}$.

\begin{tabular}{|l|l|l|l|}
\hline Sr.no. & solvent & $\begin{array}{l}\text { Conversion } \\
\text { by HPLC }(\%)\end{array}$ & Yield (\%) \\
\hline 1 & H2O : CH3CN $(1: 1)$ & 60.43 & 42 \\
\hline 2 & H2O : THF $(1: 1)$ & 62.23 & 50 \\
\hline 3 & H2O : Ethanol $(1: 1)$ & 70.99 & 48 \\
\hline 4 & H2O : DMAc $(1: 1)$ & 86.94 & 80 \\
\hline 5 & H2O : IPA $(1: 1)$ & 73.88 & 58 \\
\hline 6 & H2O : Methanol $(1: 1)$ & 84.2 & 52 \\
\hline
\end{tabular}


A optimized process for the synthesis of a key starting material for etodolac, a non steroidal anti-

\section{Experimental section}

Melting points were determined on Buchi 540 melting point apparatus and are uncorrected. FT-IR spectra were recorded as $\mathrm{KBr}$ pellet on Nicolet $380 \mathrm{FT}$-IR instrument (model thermo electron corporation spectrum one), $1 \mathrm{H}$ and $13 \mathrm{C} \mathrm{CMR}$ (proton decoupled) spectra were recorded on Varian $400 \mathrm{MHz}$ spectrometer using DMSO-d6, and tetramethylsilane (TMS) as internal standard. Mass spectra were recorded on Agilent triple quadruple mass spectrometer equipped with turbo ion spray interface at $375^{\circ} \mathrm{C}$.

\section{Preparation of 7-ethyl tryptophol,}

To a stirred solution of 2-ethylphenyl hydrazine hydrochloride(100gm) and DMAc-H2O (800ml), dropwise added 2,3 dihydrofuran $(40.7 \mathrm{gm})$ at $25-30^{\circ} \mathrm{C}$.heat the reaction mass up to $50^{\circ} \mathrm{C}$ and stirred for 30 mins. The completion of reaction was monitored by TLC. (TLC system: toluene: ethyl acetate 2:8) Added Conc. $\mathrm{H} 2 \mathrm{SO} 4()$ at $50^{\circ} \mathrm{C}$ and maintain the reaction mass for 3-4 hrs at same temp. The completion of reaction was monitored by TLC. (TLC system: toluene: ethyl acetate $2: 8$ ). After completion of the reaction, reaction mixture was allowed to cool to RT. Adjust the pH of reaction mass 4-5 by using $\mathrm{Na} 2 \mathrm{CO} 3$ solution and then extracted with MDC $(3 \times 700 \mathrm{ml})$. The combined organic layer was washed with dil. $\mathrm{HCl}$ solution, then washed with saturated bicarbonate solution and then washed with water. Dried over anhydrous sodium sulphate and concentrated under reduced pressure below $30^{\circ} \mathrm{C}$ gave crude compound. Washed the residue with cyclohexane $(100 \mathrm{ml})$. Dissolved the residue in Diiso propyl ether and passed the solution over the silicagel. Distilled out the organic layer and cooled the semisolid light yellow colour product. After cooling material was solid light yellow powder. ( $88 \mathrm{gm}$ ), yield: $80 \%, \mathrm{mp} 43-45^{\circ} \mathrm{C}$, HPLC Purity: NLT 95\%. 1H NMR (CDCl3): $\delta$ $1.40(\mathrm{t}, 3 \mathrm{H}), 1.70(\mathrm{~s}, 1 \mathrm{H}, \mathrm{OH}), 2.90(\mathrm{q}, 2 \mathrm{H}), 3.09(\mathrm{t}, 2 \mathrm{H}), 3.96(\mathrm{t}, 2 \mathrm{H}), 7.14(\mathrm{~m}, 3 \mathrm{H}), 7.53(\mathrm{~d}, 1 \mathrm{H}), 8.09($ broad s, $1 \mathrm{H}$, $\begin{array}{lllllll}\mathrm{NH}) & 13 \mathrm{C} \quad \mathrm{NMR} \quad(\mathrm{CDCl} 3) & \delta & 13.85, & 24.03 \text {, }\end{array}$ 28.88,62.62,112.68,116.60,119.82,120.76,122.20,126.68,127.15,135.32; ESI- MS : m/z (m+ -1) 190.15, IR (KBR) : 3412,2958,2725,1897,1496,1433,1357,1222,1051,748 cm-1

\section{Acknowledgement}

The authors thank Dr. hemant desai sir for the provide best guidance and encourangement.

\section{References:}

[1]. Cornford, E. M.; Bocash, W. D.; Braun, L. D.; Crane, P. D.; Oldendorf, W. H.; MacInnis, A. J. (1979). "Rapid distribution of tryptophol (3-indole ethanol) to the brain and other tissues". Journal of Clinical Investigation 63 (6): 1241-1248.

[2]. Richard Seed, J.; Seed, T. M.; Sechelski, J. (1978). "The biological effects of tryptophol (indole-3-ethanol): Hemolytic, biochemical and behavior modifying activity". Comparative Biochemistry and Physiology Part C: Comparative Pharmacology 60 (2): 175.

[3]. (a) Fenn P, Durbin R D \& Kuntz J E, Phytochemistry, 16, 1977, 899, (b) Lacan G, Magnus V, Jericevic B, Kunst L \& Iskric S, Plant Physiol, 76, 1984,889,(c) mantle P G \& Weedon CM, Phytochemistry,36,1994,1209.

[4]. Fernando I N, Francis P L \& Smith I, J Neural Transm, 56,1983,33.

[5]. Humber L G,Ferdinandi E, Demerson C A, Ahmed S, Shah U, Mobollio D, Sabatucci J, Lange B D, Labbadia F, Hughes P, Virgilio J D,Neuman G, Chau T T \& Weichman B.M, J Med Chem, 31,1988,1712.

[6]. Humber L G, Med Res Rev, 7, 1987, 1.

[7]. Neuman R G, Wilson B D, Barkley M, Kimball E S, Weichman B.M \& Wood D D, Agents Actions, 21, $1987,160$.

[8]. Budsberg S C, Waltham Focus, 9, 1999, 26.

[9]. (a) Demerson C A, Humber L G, Dobson T A \& Jirkovsky I L, US 3939178, Feb 17, 1976; Chem abstr, 85, 1976, P192696; (b) ) Demerson C A, Humber L G, Dobson T A \& Jirkovsky I L, US 4012417, Mar 15, 1977; Chem abstr, 85, 1976, P1922696.

[10]. (a) Demerson C A \& Humber L G, US 4585877, Apr 29, 1986; Chem abstr, 105, 1986, P1115045 ;(b) Qi C, Gary E T \& Lorenzo L, WO 2005/033112 A2, Apr 14, 2005; Chem abstr, 142, 2005, P373682; (c) Anderson K C \& Hideshima T, US 2006/0166947 A1, Jul 27, 2006; Chem abstr, 145,2006, P167077; (d) Lu Y-w, Lu Z-x \& Su W-k, J Chem Eng Chin Univ, 24,2010,127 (in Chinese). 